\title{
Book report \\ Bioethics in the clinic: a review of The Cambridge Textbook of Bioethics
}

\author{
Leslie M Whetstine
}

Walsh University, East Maple Street NW, North Canton, Ohio 44720, USA

Corresponding author: Leslie M Whetstine, Lwhetstine@walsh.edu

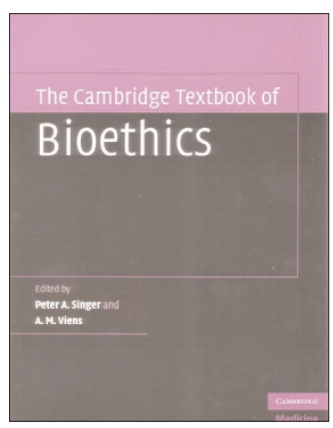

Published: 3 September 2008

Critical Care 2008, 12:307 (doi:10.1186/cc6992)

This article is online at http://ccforum.com/content/12/5/307

(C) 2008 BioMed Central Ltd

The Cambridge Textbook of Bioethics edited by Peter A Singer and AM Viens. Cambridge University Press 2008. ISBN 978-0-521-69443-8. 538 pages.

This book is specifically intended for a broad audience ranging from practicing clinicians, bioethicists, and students in the life sciences, to non-clinically oriented administrators, students in the humanities, as well as the lay public. Essentially, it is appropriate for anyone who seeks a greater understanding of the bioethical complexities that arise at the intersection of medicine, the law, and public policy. While it may seem unlikely that a book could speak to such a wide readership, it succeeds in terms of its diversity of topics and accessible thematic format.

This text is broken into well considered sections (End of Life Care, Religious and Cultural Perspectives in Bioethics, Pregnant Women and Children, and so on) that act as quick reference pointers to areas of interest associated with each theme. This allows the reader to use it without being overwhelmed by its volume, which exceeds 500 pages.

Each chapter begins with a case study, which is helpful in identifying the types of ethical conflicts that can arise in regard to the topic at hand. The case studies are revisited at the end of each chapter. While they do not always offer a clear or definitive resolution, the cases are instructive and allow the reader to integrate the material presented and reflect upon its practical application. In addition, the chapters are short and manageable (usually five to eight pages) as well as meticulously researched and offer extensive bibliographies for anyone wishing to learn more or shore up their knowledge base.

This book is not a theoretically driven work but focuses on clinical topics and concrete application. What separates this anthology from other compendia is its international and multicultural perspective. Bioethics as a discipline is not the province of any one distinct country or ethos. While this will be frustrating for the reader who is looking for the 'right' answer according to his or her geographic locale, this text does not attempt to offer a cookbook or formulaic type of ethical decision making but offers instead considered viewpoints from the perspective of its authors across the globe.

This is a comprehensive text that, in addition to addressing broad topics (informed consent, advanced care planning) and specialty clinical issues (neuroethics, infectious disease ethics), also focuses on organizational ethics and the implications brought to bear throughout the community. The chapter on Clinical Ethics and Systems Thinking deserves special mention. Here the authors describe the value of a collaborative model that integrates clinical bioethics throughout all levels of the healthcare institution rather than using it on an ad hoc basis to solve specific conflicts. Overall, The Cambridge Textbook of Bioethics is an invaluable tool for the clinician, student, professor, administrator, and patient interested in improving the quality of healthcare in any clinical setting.

\section{Competing interests}

The author declares that they have no competing interests. 